\begin{tabular}{|l|l|}
\hline $\begin{array}{l}\text { ESCOLA DE COMUNICAÇÃO, } \\
\text { ARTES E DESIGN } \\
\text { PUCRS }\end{array}$ & $\begin{array}{l}\text { FAMECOS } \\
\text { mídia, cultura e tecnologia } \\
\text { Revista FAMECOS, Porto Alegre, v. 28, p. 1-9, jan.-dez. } 2021 \\
\text { e-ISSN: 1980-3729 | ISSN-L: 1415-0549 }\end{array}$ \\
\hline https://dx.doi.org/10.15448/1980-3729.2021.1.36740 \\
\hline
\end{tabular}

SEÇÃO: CINEMA

\title{
A parataxe em Pedro Costa ${ }^{1}$
}

The parataxis in Pedro Costa

La parataxis en Pedro Costa

\section{Sebastião Guilherme}

Albano²

orcid.org/0000-0001-6059-7409

sgac@ufrnet.br

Recebido em: 31 dez. 2019.

Aprovado em: 22 mar. 2021.

Publicado em: 21 jun 2021.
Resumo: Este texto visa dar conta de um aspecto retórico do filme Juventude em marcha (Pedro Costa, 2006). Acreditamos que a figura da parataxe é um registro de confecção do texto filmico que merece ser retomado em uma interpretação profissional e designado como uma chave de leitura do mesmo. A parataxe rege as principais séries de sentido da película, que estão submetidas a imprecisões no que tange aos modelos temporais e espaciais, bem como da informação fornecida pelos personagens acerca de si mesmos ou de outrem. Isto é, lapsos temporais, espaciais e informacionais acerca dos personagens ocorrem ao longo do filme. Palavras-chave: Parataxe. Pedro Costa. Retórica.

Abstract: This text aims at pointing out a rhetoric issue of the feature film Colossal Youth (Juventude em marcha, Pedro Costa, 2006). We think that de parataxis rhetoric figure is the key of reading of Colossal Youth and the preparation of the filmic text that deserves to be taken up in a professional interpretation and designated as a key to its reading. Regarding the time and space models, the figure of parataxis lead the sense of the film, as well as the characters information on themselves and the others. Given de parataxis, time and space gaps appear all over the film. Keywords: Parataxis. Pedro Costa. Rhetoric.

Resumen: Este texto visa resaltar un aspecto retórico de la pelicula Juventud en marcha (Pedro Costa, 2006). Cremos que la figura de la parataxis es un registro de la confección del texto filmico que merece ser retomado en una interpretación profesional y designado como una clave de lectura del mismo. La parataxis rige las principales series de sentido de la película, que están sometidas a imprecisões en lo que concierne a los modelos temporales y espaciales, lo mismo sobre la información que los personajes emiten sobre si mismos y de otros. Isto é, lapsos temporales, espaciales e informacionales sobre los personajes ocurren a lo largo del film.

Palabras clave: Parataxis. Pedro Costa. Retórica.

\section{Introdução}

A retórica aristotélica encerra quarto operações (BERISTÁIN, 1997, p. 427): inventio, dispositio, elocutio e actio. Parece que os primeiros registros dessa disciplina prática que visa estabelecer normas para a consecução de um discurso datam do $V$ ano antes de Cristo (BERISTÁIN, 1997, p. 428). Neste trabalho apontaremos algumas manifestações da figura da parataxe na dispositio, na elocutio e na actio do filme Juventude em marcha (Pedro Costa, 2006), afora tocarmos em outros tópicos que problematizam os indices que o autor distribuiu ao longo da obra. Sem pontuar, trabalha- 
remos sobre a disposição de algumas figuras e temas, e na sua apresentação e execução. A parataxe atuaria como operadora de sentido entre as sequências, a sintaxe do filme, mesmas que, em alguns casos, consideramos isentas de indicações de subordinação semântica, mas não de coordenação umas com as outras. Neste caso, não haveria uma linha narrativa cuja preponderância obscurecesse as demais, apenas um protagonista forte, Ventura (Ventura), que se infiltra em tudo o que ocorre e alinhava a substância das dimensões visuais e verbais do texto filmico. Na película Juventude em marcha essa justaposição de linhas narrativas, temas ou imagens é uma marca retórica que, com efeito, encontramos também em outros filmes do realizador lisboeta, mas a qual nos dedicaremos a descrever tão somente na obra referida. Reiteramos que sua característica é abdicar da subordinação sintática e mesmo semântica, não da coordenação, como que testando a verossimilhança. Convém mencionar que no filme consideramos a sequência como o lapso temporal transcorrido entre uma unidade temática narrativa e outra, que seria a mínima unidade de sentido, tal como pode ser uma frase em um texto escrito somente. Enumeraremos mais à frente as 47 sequências que encontramos no filme.

Para Helena Beristáin a parataxe é uma figura de construção que "está entre as orações que se justapõem sem que entre elas exista subordinação [...], isto é, é a relação que liga entre si as orações coordenadas; é sinônimo de coordenação em muitos tratados e se opõe a hipotaxe, que é o vínculo de subordinação"3 (1997, p. 390, tradução nossa). Não obstante estarmos apegados a essas definições, recordamos das palavras de Jacques Rancière em O destino das imagens (2012), especialmente quando imprime um conteúdo moral a parataxes históricas, tais como algumas passagens de Madame Bovary ou de romances de Zola como O paraiso das damas e de poemas de Blaise Cendrars (RANCIĖRE, 2012, p. 54), nesta ordem. Ele revela, assim, três momentos de preponderância semântica nas determinadas sociedades que as obras dos autores citados atualizam. Nós classificamos esses momentos como: o primeiro, chamamos de tomada de consciência da burguesia, o segundo de consagração da imagem da burguesia e o terceiro de uma sua crise. Ele os elenca de outra maneira. Em Juventude em marcha, por seu turno, há uma ilusão de hipotaxe devido a que toda a história nos é apresentada sob o filtro da consciência de Ventura, o protagonista, e o momento histórico, seu cronotopo, é a destruição das comunidades de Fontainhas e Estrela d'África e a mudança de seus habitantes a apartamentos populares concedidos com subsídio pelo Governo. Acerca da confirmação da parataxe no filme, ver o artigo de Jair Tadeu da Fonseca (2008, p. 19) destaca pontos relevantes. Por exemplo, ele atesta:

Desde a realização de Casa de lava, em Cabo Verde, percebe-se a coerência das escolhas e achados estéticos e éticos de Costa, com suas câmeras geralmente fixas, sua montagem que tende à parataxe (à coordenação dos planos), mais do que à hipotaxe (à subordinação que os submete rigidamente a uma narrativa). [...] a montagem paratática promove uma associação mais disjuntiva entre os planos, pois, com o recurso da cesura (da interrupção do ritmo, geralmente lento, do plano), temos passagens cataléticas (bruscas) de um plano para outro [...] (FONSECA, 2008, p. 24).

\section{Parâmetros da coordenação}

\section{Sequências de Juventude em marcha}

1) Supostamente é Clotilde (Isabel Cardoso), esposa de Ventura, quem aparece jogando os móveis pela janela da casa de Fontainhas.

2) Clotilde, com faca em riste, conta uma história da sua infância

3) Ventura vai à casa de Bete (Cila Cardoso) falar que Clotilde não o ama mais e etc. e Bete lhe diz, sem abrir, que ele está na casa errada.

\footnotetext{
3 Do original: priva entre las oraciones que se yuxtaponen sin que entre ellas exista subordinación [...] es decir, es la relación que liga entre si a las oraciones coordinadas; es sinónimo de coordinación en muchos tratados, se opone por lo mismo, a hipotaxis, que es el vinculo de subordinación.
} 
4) Ventura vai ao encontro de Paulo Jorge (Gustavo Sampta) à saída do trabalho, onde está também Xana (Alexandre Silva).

5) Ventura e Paulo Jorge vão a um restaurante e lá Ventura diz: " - sua mãe me deixou". Mostra a ferida que a mulher fez com a faca. Comenta, ainda, que a mulher que estava lá tinha o rosto de Clotilde, mas não era ela.

6) Ventura grita o nome de Vanda (Vanda Duarte) no meio da praça, no conjunto habitacional onde ela mora, pois não sabe ao certo onde é.

7) Ventura vai à casa dela tomar cerveja e diz: "- Sua mãe não voltou pra casa". Vanda responde que sua mãe está enterrada no cemitério de Amadora. Ela diz, ainda, que gostaria de ficar com sua filha, como se a menina estivesse sob a guarda do Estado ou algo assim, o que se desmente nas sequências seguintes.

8) Ventura chega com Lento (Alberto Barros) à casa, jogam cartas e a pedido de Lento ele elabora, de cabeça, uma carta de amor.

9) Ventura acorda Lento e recita, pela segunda vez, a carta de amor.

10) Ventura está sentado em frente à casa de Bete e diz que comprou um frango quando a vê, mas ela o ignora e fecha a porta.

11) Ventura vai ver a casa nova no conjunto habitacional que o Estado financiou, mas diz que é muito pequena, pois tem muitos filhos.

12) Ventura e Vanda, em sua casa, conversam acerca do parto de Vanda.

13) Ventura espera Paulo Jorge na saida do trabalho.

14) Vão almoçar. Perguntado, Paulo Jorge diz que sua filha está na creche. Ventura diz lembrar que levava Paulo Jorge para a escola quando ele era criança e chegava em casa exausto.

15) Ventura, deitado próximo a Lento, recita a carta de amor de novo.

16) Ventura no museu. O segurança o reprime.
17) O segurança e Ventura conversam em um jardim fora do museu.

18) Ventura e Lento chegam juntos à casa. Ventura está com a cabeça enfaixada. Jogam cartas. Ventura recita a missiva de amor.

19) Vanda, Ventura e Beatriz (Beatriz Duarte), a filha, no quarto. Vanda tosse muito.

20) Ventura vai à casa de Bete. Ela diz que ele tem um filho, irmão dela, que está morto. Se chama Nhurro (António Semedo). Comenta, ainda, que ouviu que ele estava vivo na cidade do Porto, mas ela não acredita.

21) Ventura sentado em frente da casa de Bete.

22) Ventura vai à loja de móveis de Nhurro. O rapaz fala de sua mãe e seu pai. Não de Clotilde e Ventura, por exemplo.

23) Lento e Ventura. Este recita a carta de novo

24) Outra visita ao novo apartamento, desta vez com mais quartos.

25) Ventura em sua casa antiga recolhe alguns papéis.

26) Ventura vai à casa de Vanda almoçar.

27) Ventura e Lento. Ele recita a carta.

28) Ventura no apartamento novo recebe Paulo, um jovem com problemas na perna. Ventura também diz que ele é seu filho.

29) Casa de Lento e Ventura, sem ninguém.

30) Ventura compra um doce na rua.

31) Ventura sentado em um banco de praça com um rapaz ao lado.

32) Ventura, com a faixa na cabeça, e Lento, conversam na janela. Lento diz que há quase uma Guerra civil no país. Ventura recita a carta e Lento observa que já a decorou.

33) Ventura e Xana na frente da casa de Bete.

34) Ventura e Bete conversam na casa dela. 
$4 / 9$ Revista FAMECOS, Porto Alegre, v. 28, p. 1-9, jan.-dez. 2021 | e-36740

35) Ventura nos becos de Fontainhas.

36) Ventura com Paulo Jorge e Vanda na hora do almoço na casa deles.

37) Ventura enfaixado recita a carta para Lento.

38) Ventura visita outro rapaz chamado Paulo no hospital.

39) Ventura sentado na escada do edifício de Vanda. Passam por ele Vanda, Beatriz e Paulo Jorge.

40) Ventura com a faixa na cabeça na casa de Lento. Lento cai de um poste de eletricidade.

41) Ventura e Vanda veem uma novela brasileira.

42) Ventura vai à casa de Bete. Ela agora the pergunta como ele conquistou o coração da mãe dela.

43) Nos becos de Fontainhas.

44) Ventura vai à casa de Lento, que não demonstra sequelas do tombo.

45) Lento rema um barco em que está Ventura em um lago. Ventura tem a cabeça enfaixada.

46) Ventura vai à casa de Vanda e ela pede para ele ficar com Beatriz.

47) Ventura e Beatriz em casa.

No filme Juventude em marcha, à semelhança dos demais, não obstante com maior firmeza, o autor apresenta sequências que se coordenam a linhas narrativas tênues, mas não isentas de clareza, clareza essa promovida pela presença de Ventura em todas as 47 sequências que estabelecemos. Mesmo assim, no filme há uma vontade de desenvolver mais livremente os aspectos das possibilidades narrativas, e semânticas, como mencionado, e Costa se desentende, em muitas sequências, da subordinação forte que o personagem de Ventura poderia sugerir. Os tópicos da paternidade, do casamento com Clotilde, da guarda da filha de Vanda, de Nhurro e da possivel morte de Lento são alguns periodos que reordenam a sequencialidade e minimizam a espreita da hipotaxe baseada na onipresença de Ventura. Mas vamos ver com mais precisão algumas dessas indicações.
Em verdade, há quatro linhas narrativas em Juventude em marcha, todas encabeçadas por Ventura e com o tema da sua paternidade, mas com substâncias próprias e motivos da parataxe. A primeira é o seu relacionamento com Vanda. A segunda o seu relacionamento com Bete, de quem também se diz pai, sendo que ela primeiro nega essa paternidade e, depois, corrobora. A terceira, o seu relacionamento com Lento, a quem ele trata como se fosse seu filho, a despeito de não usar esse termo. A quarta, o seu relacionamento com Nhurro. Poderiamos detectar outras, porém escolhemos essas por serem operacionais em nosso trabalho. Essas linhas coincidem, em geral, devido ao comentado: Ventura se diz pai de todos eles, inclusive do esposo de Vanda, Paulo Jorge. E, também, porque, salvo Lento e Nhurro, que sequer aventam esse dado, ao princípio todos negam esse vínculo malgrado, depois assumem Ventura como pai, o que ocorre de maneira repentina e naturalizada. Esse tipo de desafio à verossimilhança é uma marca do filme, e pode ser exemplificado mais explicitamente com o que ocorre com Lento. O jovem cai de cima de um poste de luz e quase tudo indica que está morto ou muito ferido, mas sequências adiante já aparece abrindo a porta para Ventura, sem sequelas. O mesmo acontecendo com Vanda que, ao principio, diz que gostaria de ter a filha com ela, em casa, como se a menina estivesse em algum conselho tutelar ou algo semelhante em face de um antigo vício em heroina de Vanda, mas logo a pequena aparece com ela. Ocorre, devido à sequência das tomadas e cenas, um caso de parataxe, uma vez que o sucedido antes não necessariamente corrobora o plano semântico do que vem depois, mas acumula-se.

Então, as grandes linhas narrativas que atribuímos a condição de promotoras de parataxe em Juventude em marcha são:

a) Em Juventude em marcha, por exemplo, o personagem Ventura afirma ser o pai de muita gente que morava ou mora em Fontainhas, o bairro que está sendo desmantelado pelo Governo e seus habitantes trasladados a conjuntos 
habitacionais de baixa renda. Mas nem sempre seus interlocutores admitem ser filhos dele, tal como ocorre com Bete (sequência 3), Vanda (sequência 7) e Nhurro (sequência 22). Malgrado o tema da paternidade esteja latente, às vezes não se confirma essa circunstância, às vezes sim, em um processo de pouca subordinação e muita coordenação que corrobora essa dinâmica das sequências e problematiza a mimese e a verossimilhança;

b) Outro ponto de indeterminação é a guarda da filha de Vanda, Beatriz (sequência 7). Primeiro Vanda diz almejar que a filha fique com ela e não sob a custódia do Estado (?), mas algumas sequências depois a menina aparece com ela e seu esposo e assemelha gozar de uma infância comum, indo à escola, brincando com os pais na rua etc. (sequências 14, 19, 46, 47). Isto é, como se nunca houvesse ficado sob a custódia do Estado;

c) O caso de Lento é outro. Desde o principio se sabe que Lento pode ser mesmo filho de Ventura, malgrado não se mencione e o rapaz se refira a ele como Ventura e não como pai. Portanto, nosso interesse aqui se dirige a quando ele sofre o acidente (sequência 40) e, em seguida, aparece (44 e 45) sem nenhum sinal de consequências da queda. Ademais, há interpretações que consideram Lento e Ventura a mesma pessoa, ou que Lento morreu duas vezes etc. (GALLAGHER, 2009, p. 40-51). O fato que o filme mostra é que ele, ao cair, não parou de mexer os olhos, em uma demonstração de sinais vitais. E, como reaparece, pode não ter morrido;

d) Ventura não é o pai de Nhurro, em que pese Bete (sequência 20) afirmar que tinha um irmão, e ele um filho, que se chamava Nhurro que havia morrido etc. Reiteramos: Bete fala de Nhurro como sendo um filho morto de Ventura e seu irmão, mas essa informação não procede, pois Nhuro está vivo (sequência 22), ou ao menos aparece na história, e faz constantes alusões a seus pais em Cabo Verde.

\section{Generalidades da parataxe}

A obra de Pedro Costa a partir de No quarto de Vanda (2000) é filmada com câmera digital e, dentre outras marcas estilisticas, também começam a escassear ainda mais os campos/contracampos, sempre pouco acionados pelo realizador. Em Juventude em marcha, por exemplo, cremos ser apenas 3 (um com Bete e Ventura, sequência 42, e dois com Lento e Ventura, o primeiro na sequência 9 e o segundo na sequência 37). Mas o que urge um comentário mais apurado, mas este trabalho não se propõe a tal, estaria relacionado com o elemento colonial e pós-colonial em suas películas. Desde seu segundo longa, Casa de lava, Costa se aventura pelos meandros da solidariedade pós-colonial, ensejando interpretações próximas a atribuir-lhe uma espécie de culpa retrospectiva pelo passado metropolitano de Portugal em relação a seus domínios de ultramar. Sente-se uma faísca deste remorso nos espaços selecionados nos filmes. Todavia, esse afeto, esse pathos, culpa/ solidariedade, tão somente ganha certo corpo em Casa de lava, em razão de a enfermeira Mariana (Inês de Medeiros) ir até a Ilha do Fogo, vulcânica, em Cabo Verde, para acompanhar um imigrante, Leão (Isaach de Bankolé), paciente grave que deve ter-se ferido em alguma obra em Lisboa, pois, como citamos, o motivo da solidariedade é uma constante em seus filmes (lembrar de Ossos). Na maior parte em chave naturalista, a obra de Pedro Costa parece atingir sua autonomia ética e estética com sinais que mesclam o passado histórico do Portugal colonial com suas terras de além-mar e uma Lisboa pensativa ou mesmo amuada por isso. O personagem de Ventura e os bairros de Fontainhas e de Estrela d'África e a realocação dos seus habitantes em conjuntos habitacionais incorporam esse fato.

Não devia ser desconcertante, mas é-o sempre em Juventude em Marcha: conta-se uma história. A confusão acerca de coisas como a revolução, a democracia, o parentesco, a memória e a casa está presente e é apresentada. Se o sólido suporte narrativo do filme torna esta confusão concreta, e Juventude em Marcha 'milita enquanto cinema' (Daney), 'fá-lo apenas através de uma alucinação que é verdadeira'(Bazin). No cinema, como na história (RECTOR, 2009, p. 207). 
Com efeito, uma interpretação razoável para o que se vê em Juventude em marcha passa pelo crivo da memória de Ventura, que interpreta as lutas intestinas no império português da perspectiva de um operário que, desde 1972, está em Lisboa e que voltava do trabalho todos os dias para casa embriagado. Portanto, a Revolução dos Cravos, de 25 de abril de 1974, foi-lhe não indiferente, mas absorvida de forma enviesada, bem como a Revolução de Independência de Cabo Verde, a 5 de julho de 1975. Isso explica porque sua atitude política não administra as ferramentas dos grandes acontecimentos, mas padece um processo de biopolítica. Ventura não conta sua história e dos seus achegados por intermédio dos eventos vultosos, mas esses eventos contam a história de Ventura e dos cabo-verdianos que habitam Estrela d'África e Fontainhas. Por isso, a figura da parataxe é tão relevante, pois a memória, muitas vezes, não é sequencialmente ordenada, mas a saltos e fragmentos plasma sua narrativa. A parataxe em um discurso como o filme pode dar conta desses detalhes que de outra maneira passariam despercebidos. Mas Ventura e seu discurso têm mais sentido se os virmos por intermédio de um filtro retórico e mediante a parataxe, pois ele mesmo se confunde com as mulheres, com os filhos, com as portas, exigindo que o sujeito ordenador do discurso, o narrador, o realizador etc., lance mão de estratégias que fornecem inteligibilidade a sua corrente memorialística sem que essa perca sua especificidade. Inclusive, para alcançar um tal resultado, Pedro Costa remete a um tipo de representação que tende a se tornar autônoma no mesmo sentido em que Rancière recorda Hegel quando diz que alguns quadros de autores românticos holandeses rompem com os fios da representação "que os atavam à reprodução de um modo de vida repetitivo" (RANCIĖRE, 2012, p. 87). E mais: "É a expressão de outra autonomia, a que o Povo holandês soube conquistar [...]" (RANCIĖRE, 2012, p. 87). Daí que essa passagem de Rancière demonstra contato com essa conquista de autonomia representativa ou apresentativa e também com uma certa herança flamenga na iluminação dos filmes de Pedro Costa. Portanto não é gratuito em que nas sequências em que Ventura está no museu da Fundação Calouste Gulbelkian (16 e 17) veem-se óleos de Rubens e Van Dyck.

A memória de Ventura parece mesmo permear o filme completo, afinal ele rege as 47 sequências, em que pese haver, como vimos, outras linhas narrativas que inclusive guardam uma espécie de quase subordinação, hipotaxe subliminar ao que ocorre a Ventura ou do que Ventura se lembra. Contudo, essa quase subordinação é substituída, em um lance retórico, por fragmentos que a colocam sob a égide da parataxe, pois Juventude em marcha está montado com relatos soltos com base na triagem de Ventura (Vanda e a filha, Lento e a queda, Bete e Nhurro, os filhos), que perpassam sua consciência. A iluminação pictórica favorece esse ensimesmamento do filme em Ventura, que em se subtraindo as sequências em que está no pátio ou nos apartamentos de o Casal da boba, nome do novo lugar muito claro em que foram construidos os prédios para albergar os ex-habitantes de Fontainhas e Estrela d'África, aparece sempre sob um modelo de luz do tipo chiaroscuro. Esse esquema de composição da imagem vai em favor dos entreditos e projeta um mundo observado por uma mentalidade turva ou uma perspectiva memorialistica, em interpretação livre. Que outro ponto de vista poderia ter um exilado cabo-verdiano que trabalhou a juventude e a fase adulta em obras em Portugal, chegando sozinho ao final da vida? Mas devemos observar que esse claro/escuro também projeta a luminosidade parca predominante de um bairro composto de vielas e becos e casas mal construidas ou mesmo improvisadas. Pelos anos de Fontainhas, Ventura não parece se adaptar à higienização do Casal da boba, e dorme no chão do apartamento novo, não tem móveis, entre outras excentricidades.

Por isso dizemos que os próprios espaços em que se movem e vivem os personagens dão conta de uma degradação que só poderia ser forçada e representada como manifestação de culpa, mas que nos filmes de Costa ganham outra dimensão. Se a imagem que temos das ilhas que pertenciam a Portugal, o arquipélago 
de Cabo Verde por exemplo, é de um espaço paradisiaco, esse dado permanece na feição nostálgica de todos os personagens negros do filme, que estão sempre a desejar alhures, mas parecem relutar em sair de Fontainhas, como Ventura. São personagens desterritorializados e reterritorializados que assemelham não encontrar chão firme em que pisar, pois o exilio não thes fornece bases para isso, uma vez que se não são mais escravos, tampouco são livres para viver mais plenamente as benesses do mundo contemporâneo, e aceitam uma espécie de degredo com roupagem espontânea, mas talvez tão violento quanto a alienação escravagista de antes. A relevância que Pedro Costa imprime aos lugares (Fontainhas, Estrela d'Àfrica, Casal da boba, os interiores dos bairros e das casas) pode sugerir remarcar essa dissipação dos valores, pois a câmera e a luz naturalistas, quase expressionistas, minimizam qualquer pretensão de heroísmo, mas sua fotografia não está isenta de vida e até chega próximo a gerar certa beleza estoica. Deleuze tem uma passagem sugestiva a respeito da espacialidade em certos filmes de Antonioni que se enquadra em nossas reflexões acerca de Juventute em marcha. Ele diz que nos filmes do italiano "O espaço não fica despotencializado, mas, pelo contrário, fica muito mais carregado de potencial" (2004, p. 165). Com Costa, os interiores de Fontainhas estão prenhes de sentido, mesmo vazios de móveis e de gente, já no período da demolição. Parece que ali o tempo cinematográfico se abstrai ainda mais. "[...] o conjunto amorfo é com efeito uma coleção de lugares ou de sítios que coexistem independentemente das ligações e orientações que the davam as personagens e a situação desaparecidas" (2004, p. 166). No caso de Juventude em marcha a parataxe propicia esta combinação de sentidos.

Em compensação Vanda se enquadrou, submetendo-se a um processo de cura ofertado pelo governo que inclui a aquisição gratuita de metadona. Vanda, ainda que mais fornida que em Fontainhas, mas com a mesma tosse de asmática, parece mais feliz agora, com a filha Beatriz, com o apartamento, casada com Paulo Jorge etc. Seus encontros com Ventura são permeados de saudades da mãe, da irmã, do camarão que comprava para comer com cerveja, mas ela demonstra em seus relatos uma claridade solar que não deixa imprimir um tom triste ou onírico ao que narra. Vanda se tornou outra pessoa fora de Fontainhas. Precisamente o que Ventura não consegue fazer, apegado ao pretérito em seu relato, memorialista, reiteramos, vaga em busca de compreensão da sua vida, crendo ser pai de quase todos os personagens e ter sido deixado recentemente por sua esposa Clotilde. Ele mesmo está cônscio de sua indeterminação, mencionando que sempre bebia muito, a ponto de sair do trabalho na construção e ir para a casa de alguma mulher, pois se confundia com os caminhos, com as portas. Não é Ventura que não sai de Fontainhas, mas o contrário, é Fontainhas que não sai dele. Pareceria que esse aspecto vai além da figuração, além da parataxe que ordena o filme, mesmo que só a parataxe o possa exprimir, devido a que Juventude em marcha é uma espécie de continuação, parte final de uma trilogia, uma vez aceitando-se o caráter documental que o filme sugere e sua natureza de corolário: Juventude em marcha é impensável sem Ossos (1997) e sem No quarto de Vanda (2000), em especial sem o último.

É precisamente este caráter documental e sua tradição entre os cineastas portugueses (por exemplo, Manoel de Oliveira, João César Monteiro) que possibilitam a narrativa do filme com explícita e peculiar estrutura histórica. Em Costa, ele insiste na ida dos imigrantes cabo-verdianos para Lisboa e Porto para trabalhar na construção e sua invisibilidade no tecido social português. Segundo Pardue "A história de Portugal é, em grande parte, uma narrativa acerca de encontros 'civilizadores' e o cultivo do caráter nacional através desses encontros em locais distantes" $\mathrm{E}$ decreta: "Este é um filme sobre a gestão da alteridade"4 (2014, p. 59, tradução nossa). Não fala de Juventude em marcha, mas poderia. O cinema

4 Do original: Portugal history is in a great part a narrative about 'civilizing' encounters abroad and the cultivation of national character through such meetings in far-flung locales / it is a film about the management of otherness. 
português demonstra ser um espaço de reflexão para as ondas de mestiçagem que, de tempos em tempos, ocorrem no pais. Em No quarto de Vanda vemos, de novo, sob a lupa naturalista, como o consumo de drogas infiltrou-se nesses estratos e, em Juventude em marcha, como houve quem morresse e quem se transformasse devido a esse fenômeno. O mesmo ocorre com o tema da habitação. Antes, Fontainhas, agora Casal da boba. E o realizador consegue observar todo esse movimento e criar uma narrativa para ele, sob uma perspectiva de autor/autoridade, mas querendo recusar seu mundo burguês e delegar a voz a Ventura, a Vanda, sem conseguir por completo, ainda que logrando grandes momentos. Não queremos aqui entrar no mérito da frutifera sociologia do artista (FRANCASTEL, 1993) e, tampouco, no jogo de espelhos entre mundo da vida e obra de arte. O fato é que, por intermédio da parataxe, esse conflito que já está para além da dialética se apresenta.

\section{Considerações finais}

Vimos que a parataxe, uma figura de coordenação, apaga as possibilidades da hipotaxe, figura de subordinação, em Juventude e marcha, em razão de uma dispositio, uma elocutio e uma actio realizadas em fragmentos de informação e, digamos, desinformação ao longo do filme. Esse dado imprime um caráter de desestabilização da mensagem semântica verbal, mas não altera, em geral, a unidade do estilo visual do autor, baseado no expressionismo, na câmera parada e na técnica do claro/escuro. No filme, iluminação, direção de arte, escala e duração dos planos mantêm-se estáveis, mas não chegam a caracterizar uma hipotaxe, em face de que esses elementos e a montagem reiteram o ponto de vista de Ventura, que se lança a uma jornada memorialística bastante descontínua, solicitando de um e outro ex-moradores de Fontainhas sua colaboração na feitura de seu ideal de passado, com muitos filhos. A fixação de Pedro Costa por Ventura se baseia nesse aspecto, na possibilidade de verificar e (des)verificar a informação que o homem fornece, possibilitando a transação dos tempos, dos espaços e dos dados relatados sem muita preocupação com a serialidade dos fatos, mas com fidelidade à memória de Ventura. Essa fixação poderia ser mal-interpretada como a inevitável culpa/solidariedade que se diz própria dos portugueses com os africanos das ex-colônias, mas isso não chega a se solidificar, em muito porque nem o diretor parece querer e nem o personagem Ventura se prestam a esses afetos ou mesmo a esse modo de sociabilidade. A iconografia e o cronotopo dominantes no filme reportam a essa história social que retira os desabonados de um local marginal, onde poucos pagam as contas dos serviços públicos, e os trazem à luz para os incorporar ao mundo dos impostos sobre a água, a eletricidade, o gás, o aquecimento, a manutenção dos espaços comuns etc.

\section{Referências}

BERISTÁIN, Helena. Diccionario de retórica e poética. 8. ed. México: Porrúa; UNAM, 1997.

DELEUZE, Gilles. A imagem-movimento. Cinema I. Lisboa: Assírio \& Alvim, 2004

FONSECA, Jair Tadeu. A recusa do esquecimento inevitável. Devires, Belo horizonte, v. 5, n. 1, p. 14-25, jan./jul. 2008.

FRANCASTEL, Pierre. A realidade figurativa. São Paulo: Perspectiva, 1993.

GALLAGHER, Tag. Straub anti-Straub. In: CABO, Ricardo M. (coord.). Cem mil cigarros. Os filmes de Pedro Costa. Lisboa: Orfeu Negro, 2009. p. 40-51.

JUVENTUDE em Marcha. Direção e roteiro: Pedro Costa. Producão: Contracosta. Intérpretes: Ventura; Beatriz Duarte; Gustavo Sumpta; Cila Cardoso; Isabel Cardoso: Alberto Barros "Lento"; António Semedo Nhurro; Paulo Nunes; José Maria Pina; Paula Barcelos. Fotografia: Pedro Costa e Leonardo Simões. Som: Olivier Blanc. Montagem: Pedro Marques. Lisboa: ContraCosta, 2006. (156 min.), son., color., digital.

NO QUARTO de Vanda. Direção: Pedro Costa. Produdores: Francisco Villa Lobos; Kaul Baugarten; Andrés Pfaefli. Intérpretes: Vanda Duarte; Zita Duarte; Lena Duarte; Miguel Gomes Miranda; Diego Pires Miranda; Evangelina Nelas; Miquelina Barros; António Semedo; Paulo Nunes; Paulo Jorge Gonçalves; Fernando Jorge Paixão. Fotografia: Pedro Costa. Montagem: Dominique Auvray. Portugal: Contracosta, 2000. (171 min), son., color., digital.

OSSOS. Direção e roteiro: Pedro Costa. Produção: Paulo Branco. Intérpretes: Vanda Duarte; Nuno Vaz; Isabe Ruth; Inês de Medeiros; Miguel Sermão; Berta Susana Teixeira; Clotilde Montron; Zita Duarte; Beatriz Lopes e outros. Fotografia: Emmanuel Machuel. Som: Henri Maikoff. Montagem: Jackie Bastide e Paulo Barbosa. Lisboa: Madragoa, 1997. 1 bonina cinematográfica (97 min.), son., color., $35 \mathrm{~mm}$. 
PARDUE, Derek. Outros bairros and the Challenges of Place in Postocolonial Portugal. In: REGO, Cacilda; BRASILEIRO, Marcus. Migration in Lusophone Cinema. Nova York: Palgrave, 2014. p. 59-75.

RANCIĖRE, Jacques. O destino das imagens. Rio de Janeiro: Contraponto, 2012.

RECTOR, Andy. Pappy. A rememoração dos filhos. In: CABO, Ricardo M. (coord.). Cem mil cigarros. Os filmes de Pedro Costa. Lisboa: Orfeu Negro, 2009. p. 206-231.

\section{Sebastião Guilherme Albano}

Doutor em Comunicação pela Universidade de Brasília (UnB) em Brasília, DF, Brasil, com bolsa da CAPES. Mestre em Letras Latinoamericanas pela Universidad Nacional Autónoma de México (UNAM), na Cidade do México, México, com bolsa da Secretaria de Relaciones Exteriores de México (SRE); professor associado da Universidade Federal do Rio Grande do Norte (UFRN), em Natal, RN, Brasil; pesquisador da Sociedade Brasileira de Estudos Interdisciplinares da Comunicação. Pós-doutor pela UNAM e na University of Texas (UTAustin), em Austin, Texas, Estados Unidos, com bolsa da CAPES; e no Instituto Superior de Teatro e Cinema do Politécnico de Lisboa (STCPL), em Lisboa, Portugal, com visita técnica à Universidade do Texas em Austin.

\section{Endereço para correspondência}

Sebastião Guilherme Albano

Universidade Federal do Rio Grande do Norte

Av. Salgado Filho, 3000

Lagoa Nova, 5907-8900

Natal, RN, Brasil

Os textos deste artigo foram revisados pela Poá Comunicação e submetidos para validação do autor antes da publicação. 